\title{
Occupational Health: A Bibliometric Study on Stress
}

\author{
Alexandre Rodrigues Inácio de Azevedo \\ Universidade Federal de Minas Gerais, Brasil \\ E-mail: azevedo.alero@gmail.com \\ Adriana Maria Lamego Rezende \\ Universidade Federal de Minas Gerais, Brasil \\ E-mail: adrianalamegorezende@gmail.com
}

Matelane dos Anjos Rezende

Universidade Federal de Minas Gerais, Brasil

E-mail: matelane71@gmail.com

\author{
Jéferson Valente Vieira \\ Universidade Federal de Minas Gerais, Brasil \\ E-mail: jeferson.vieira@ebserh.gov.br
}

Elaine Santana de Souza Ferreira

Universidade Federal de Minas Gerais, Brasil

E-mail: elaine.ferreira@ebserh.gov.br

Received: Oct. 2, 2019 Accepted: Oct. 30, 2019 Online published: Nov. 20, 2019

doi:10.5296/ijhrs.v9i4.15864 URL: https://doi.org/10.5296/ijhrs.v9i4.15864

\begin{abstract}
Occupational stress is responsible for numerous diseases in the behavioral, physiological, psychological and social field of workers. This study has as main objective to analyze the content of the works referenced, through bibliographical analysis, qualifying and quantifying
\end{abstract}


the data collected on the work stress in the organizations of the present time, from the perspective of the scientific community. Firstly, the concepts, causes and consequences of occupational stress were identified, presenting solutions in the context of human rights, based on the analysis of the predictors of efficacy. Then, the method used was a bibliometric survey, based on electronic research platforms SPELL and SciELO and searching for the keywords were found 167 articles in the last ten years to find out which are the most researched areas on stress, what types of research and what groups are most searched. From the data collection, a quantification of the data was performed. The justification for this research was the authors' interest in contributing to the scientific community and to the groups of workers who are daily exposed to stressors. It could be concluded that stress is extremely dangerous for physical and mental health, as well as for organizational development. Harassment, totalitarianism, prejudice and exclusion are one of the main factors that lead the individual to work stress. In addition, based on research in Scielo alone, the Public sector is the one that most has research related to stress, with $46 \%$ of articles analysed. The Health area has the largest number of publications, with $50 \%$ of publications. Together, the qualitative and bibliographic researches account for 38\%, against $62 \%$ of publications of quantitative methodology. This does not mean that stress is exclusive to public health workers, but an indication that the private sector lacks research related to organizational illness.

Keywords: Occupational Stress (OS), Workplace Stressors (WS), Organizational Violence (OV)

\section{Introduction}

The word stress emerged in the English vocabulary linked to physics, through the state of deformity of a material, when it is subjected to an effort or external force. Later, this concept was adapted to medicine due to the result presented by the human organism, when it has to face situations of threat to its internal equilibrium. Entrepreneurs say that certain degree of stress is interesting to accelerate the production process, so it has become the evil of the 21ST century, opening doors to a multitude of physical and mental illnesses to workers (Pereira \& Mello, 2016).

According to psychiatry Dr. Maristela C. Sousa (2017): "[...] Stress is an effort to adapt the organism to face situations considered threatening to life and its internal equilibrium [...] ". In all phases of stress people seek movement, especially in the skills they value, but some activities or situations produce unwanted effects, such as: emotional tensions, physical symptoms and decreased performance in Work, because stressful factors are adverse to the human organism (Sousa, 2017).

The authors Silva and Salles (2016) say that stress arose in modern times because people spend most of their lives at work, without time for leisure with family and friends, which did not occur in the early days of mankind. The reality is that the work acquired meaning of status, of personal accomplishment, of its recognition and identification as the center of People'S lives (Silva \& Salles, 2016).

Occupational stress is linked to several interconnected variables, which are responses to 
stimuli from the workplace, "unhealthy" reactions of people exposed to them. The tendency of employers is to consider this type of stress as a process conceived by stressors that respond according to a "relational concept", pre-established by certain opposing groups to the work environment and to companies (Paschoal \& Tamayo, 2005).

The reality is that occupational stress has become a growing epidemic of this century, which has already reached managers, managers, employers and organizations, provoking attempts to manage stress at work and its consequences on health. But they are insufficient and unsatisfactory because they aim more at reducing the effects of stress than the extinction of stressors (Tamayo, 2001).

There are a multitude of causes of occupational stress: The changes (social, economic, technological); The weathering of time and life (illnesses, accidents, loss of loved ones); The effects of external conviviality (family, friends); The inclusion and Social exclusion criteria (miscellaneous prejudices and so on); Individual and group factors in the work environment; Abuse Environmental/structural inconsistencies. Finally, all factors considered as the biological, psychological and sociological aspects that because stress are distinct, complementary and interconnected (Prado, 2016).

However, the undesirable factors to the human organism lead individuals to affective, emotional and intellectual processes, which correspond to the way they relate to people and the world around them, which are the variables that are established in Context of society. The signs and symptoms of the stress stages should be subjected to a specialized clinical diagnosis, from the screening of the individual and the risks in the work situations. In this case, both should be treated appropriately, simultaneously (Prado, 2016).

On the other hand, we need to consider that modernity has not been able to extinguish or reduce the barbarism of man against his fellow person, as a permanent and present in society and in organizations. There is barbarism that we find incorporated into the efficiency of mass production, called "Productive force"; another remains in the interlines of "professional competence" unprecedented; and finally, we find the one that disguises itself as " Authoritarian power ", which is able to extinguish the" self-love "of the underlings and collaborators through the disrespect of human rights, unacceptable by the world population (Meneghetti, 2018).

In this context, considering all the considerations cited, it became important and pertinent to carry out this study in order to clarify the following guiding question: what are the causes and consequences of occupational stress and what are the measures to be taken, in addition to the clinical diagnosis and treatment of the worker? To answer this question, we had the basis of the study the content of the selected bibliographical works, from which it was possible to reach the conclusion. It was a way of bringing evidence and perspectives to light in an analytical way.

This study is organized in chapters presented here in the form of ' titles ', where the approaches were developed respecting the following steps: formulation of the problem; Construction of the guiding question; operationalization of variables; Localization of the 
investigated groups; submission to the methodology; Interpretation of the data; Content development; And conclusion of the study.

The methodology used here is bibliographic using the bibliometric technique, as instruments and procedures that will qualify and quantify the facts to interpret the problem. There are different designs of collecting, transcribing and analyzing information from different methodological approaches.

The main objective of this investigation is to analyze the content of the referenced works, qualifying and quantifying the data collected about occupational stress in today's organizations, from the perspective of the scientific community. The secondary objectives are summarized: to identify the concepts of occupational stress, under the view of psychiatry and medical clinic; Relate the main causes and consequences; and present the appropriate solutions in the socio-political context and human rights, analyzing all the predictors of efficacy.

The main justification to produce this work was the authors ' interest in contributing to the scientific community and to the groups of workers, who remain exposed and/or are victims of occupational stress in organizations, with a focus on Brazilian companies.

\section{Occupational Stress}

The study by psychiatrist Dr. Maristela C. Sousa (2017) on occupational stress presents the following phases: 1) alarm reaction; 2) Resistance; and 3) exhaustion, all of which result in unwanted effects such as emotional tensions, apparent physical symptoms, and decreased professional performance, among others.

The "alarm reaction" phase is the one in which the body, through a physiological state of aggression, initiates the immediate activation of the hypothalamus with consequent effect on the adrenocorticotrophic hormone (ACTH), which is the main regulator of the production and Cortisol secretion. In response to ACTH release, the pituitary gland releases the Corticotrophin $(\mathrm{CRH})$. Then, the suprarenal Medulla responds by increasing the secretion of catecholamines (adrenaline and noradrenaline), responsible for increased respiratory rate, heartbeat and blood pressure, as well as elevation of blood flow to the muscles, inhibition of digestion and pupillary dilatation. Consequently, the suprarenal cortex, in turn, increases the secretion of corticosteroids to release the stored energy, reducing inflammation and reducing the immune system response, which are the common effects observed in cases of stress by Prolonged time (Sousa, 2017).

The reality is that the individual who is often stressed becomes a ticking time bomb, ready to implode and explode. The alterations observed in the organism in the first phase of stress are: increased heart rate and blood pressure; Spleen contraction; Glucose release by the liver; blood redistribution; Increased respiratory rate; Dilatation of the bronchi; Pupil dilation; and increase in the number of lymphocytes in the bloodstream (Sousa, 2017).

In the second phase, which is the one in which the organism seeks to adapt its maintenance by an alarm; the symptoms are muscle tremor; Physical fatigue; Discouragement Irritability 
Difficulty concentrating; and emotional instability. In the third and final phase, in which there are flaws in the mechanism of adaptation and deficit of the reserves of energies, causing a decrease in immunity and trends to death one can observe the following reactions: respiratory problems; gastrointestinal disorders; Hypertension Sudden infections; Depression and many other reactions, which could lead the individual to death (Sousa, 2017).

The intrinsic factors for stress-generating work can be caused by:

1) Conditions: of unhealthy; journey and pace of work; potential risks to workers ' health; work overload; introduction of new technologies; or by nature and content of the work itself;

2) Role of the individual in the organization: ambiguity; conflicts; insecurity; and paper overload;

3) Inter-Relationship: towards the superiors; colleagues; and subordinates;

4) Factors related to career development: status congruence; employment security; and prospects of promotions;

5) Climate/structure of the organization: potential threats to the integrity of the individual, his autonomy and personal identity;

6) Home/Work Interface: Common aspects between occupational stress and external personal events, i.e., is the macro and psychosocial dynamics of stress.

They are called "occupational stressors" the stimuli generated from stress at work, which have negative physical or psychological consequences to the human organism. They have become the paradox of modern organizations because people seek opportunities for personal growth, skills development and group relationships for lack of security, ambiguity, competitive demands and/or pressures (Sousa, 2017).

Psychiatry explains that stress alone is incapable of triggering an organic disease or provoking a significant dysfunction in the human organism. However, due to the organic conditions of dissatisfaction and vulnerability, the individual is incapable of evaluating and facing the stressful situation, being exposed to eventual pathologies and mental imbalance (Sousa, 2017).

\subsection{Symptoms of Stress}

The main symptoms of occupational stress are physical, psychological and behavioral (SOUSA, 2017):

a)Physical symptoms: Cardiovascular symptoms such as elevated blood pressure, tachycardia and palpitations; alteration of biochemical measures such as increased cholesterol and uric acid levels; symptoms associated with the etiology of diseases and disorders Organic Gastrointestinal symptoms such as peptic ulcers and diarrhea; 
b) Psychological symptoms: dissatisfaction with work; more intense affective states such as anger, frustration, hostility and irritation; more passive reactions, but perhaps not as negative as boredom, exhaustion collapse, fatigue and depression; reduction of Self-confidence and self-esteem; Absence of pleasure, which is replaced by a feeling of emotional numbness; Mental disorders (anxious, phobic, obsessive-compulsive, somatoform such as hypochondria or persistent pain, adaptation - PTSD, depressive, neurasthenia, food, sleep, sleep-wake, alcoholism, drug addiction, smoking, Burnout , Psycho-paranoid, absenteeism, and presenteeism);

c) Behavioral Symptoms: low performance; accidents; use of drugs at work; antisocial behavior such as theft or intentional damage; Escape from work: absenteeism and turnover; degradation of other roles of life: aggression of spouse or Playground Harmful auto Behaviour: abuse of alcohol and drugs.

The strategies to administer stress is the process of evaluation and coping ${ }^{l}$ : The evaluation is the judgment on what can be done to minimize the damage caused by stress or maximize gains with the treatment; and the Coping is summarized in strategies for coping with stress, which are defined as a set of cognitive and behavioral efforts, used by individuals in order to deal with stress situations, which are overloads that exceed To the resources of the organism (Sousa, 2017).

\subsection{Main Causes of Occupational Stress}

According to the World Health Organization (WHO) in a study on the events that cause stress in workers-February $2019^{2}$ Report, it pointed out as preponderant factors that cause stress in worker man, masculinity and Gender equality. We can relate as the main causes of occupational stress the following conditioning factors:

a) The transit and the fulfillment of working hours: which may be a matter of lack of road infrastructure; diseases caused by environmental pollution; physical problems resulting from accidents and frequent pathological disorders such as arthritis and arthrosis; Fatigue and irritability with wasted hours in traffic jams. Already the pressures for time and work overload for increased production are urgency of tasks that should be produced in short time; excessive liability; and lack of support in individual work, which frightfully increases stress levels (Pereira \& Mello, 2016);

b) Inadaptation to organizational changes: by new management or changes in the work process, or due to administrative merger or by implementing a new business plan. There are people who have the ability to adapt to new models of work, but there are other well-preserved ones who feel pressed with modifications in the company, even

\footnotetext{
${ }^{1}$ Strategy of Coping or coping are efforts Cognitive and behavioral issues to deal with damage, threat or challenge situations when a routine or an automatic response is not available.

${ }^{2}$ World Health Organization on February 25, 2019. Theme: "The importance of addressing men's masculinity and health for universal health and Gender equality". Available for: $<$ https://nacoesunidas.org/?post_type=post\&s=ESTRESSE>.
} 
if they have improvements. The new information technologies are the ones that most cause discomfort in people (Cataldi, 2015);

c) The lack of security in employment: Instability in work leads many individuals to despair by the fear of losing their livelihood to themselves and to the family. Nowadays, most work environments present a frightening future for their employees, who, in turn, work under pressure and fear (Pereira \& Mello, 2016);

d) Unsatisfactory remuneration: the remuneration is made up of salary, monies, additional credits, overtime, gratuities, bonuses, commissions, and other sources that are configured in factors of satisfaction and motivation of employees. It is the result of the physical, mental and intellectual efforts of the individual, who will bring comfort and well-being to you, family and friends, and when there is this type of dissatisfaction the productivity will be automatically compromised. There is absenteeism, demotivation at work, reduction of profits and installation of stress (Pereira \& Mello, 2016);

e) Worn relationships: relationships at all levels compose the work environment and can erode people and may even generate a scenario of uncontrollable aggression. Typically, this wear is generated by disputes over promotions among employees; Miscarriages and/or pranks misunderstood among people; Sarcasm Meaningless discussions; Work without cooperation; inadequate policy approach; Competitions without planning; Bad division of workload; Finally: It is the management of people and production by incapacitated (Amaral, 2013);

f) Authoritarian management: "[...] Poorly managed working groups are on average $51 \%$ less productive and $44 \%$ less profitable than those that are well directed [...] " (Pereira \& Mello, 2016), 2016, p. 153). However, there are organizations that consider their employees as part of the financial and intellectual resources, taxable persons that need to be administered. In this item we can find the rigidity with inadmissible rules such as the exploitation of the effort, both in the workload and in the nature of the work, to the point of hurting human rights (Pereira \& Mello, 2016);

g) Totalitarianism: the "totalitarian system" arose from the collapse of the traditional system of classes, which are the heirs of the nationalist ideologies of "racial roots", which present themselves as "natural defenders of the masses". These are groups that form a bulky "social body", which is said to advocate standards to please a minority, where they absorb the totalitarian movements only to reveal that they have control over a "mass" of the population, and are mixed with various movements, Can come to abominable attitudes and even to crime. There are totalitarian organizations that institute this culture and subtract everything from employees, always leading them to the last level of stress (Silva, 2010);

h) Physical-Structural disorganization: It may be in the inadequacy of structures or in information truncated or difficult to access; lack of staff training; sudden changes of tasks; or objectives without clarity. It is necessary to integrate the teams in the 
company's objectives through the implementation of an appropriate internal marketing project: It is the view that the employee is the internal client that needs to be conquered, so that he can come to retain the external client (Cataldi, 2015);

i) Absence of stimuli and perspectives: Usually this occurs when the stress reaches the second and third phase, where the individual has already lost all prospects of work and even life opportunities, reaching depression and total demotivation (Amaral, 2013);

j) Inadequate environmental factors: noise; poorly distributed lighting; very hot or cold temperature too much; very humid environment; poorly distributed or inadequate ventilation; lack of equipment needed for work or inadequate. In this item we can add as more susceptible activities: nursing care; The weathering of police officers; The exposure of laboratory technicians, radiology, Civil construction, ink industries and corrosive products, tenements, mining, and many others. The question is not the activity, but the lack of environmental and structural conditions for the accomplishment of the work, for example, the absence of personal protective equipment (PPE), and others (Costa; et al., 2007);

k) Repetitive activity and ant physiological posture: The permanence for excessive time in tiring activities or requiring an inadequate posture for that individual may cause discomfort that generate stress as pain located in the spine or in other Body structures; The unmet physiological needs; and etc. Repetitive activities are considered illicit, but modernity has brought the pathologies of the services such as telemarketing, shopping vendors, general services of façade cleaning, at last: too long standing or sitting or in Exposure to dangerousness or unhealthy, which are stressful factors that generate associated pathologies such as hypertension; Poor blood circulation; Kidney, hypogastrium, respiratory, cardiac, and many other problems (Herkenhoff, 2007);

1) Slave service: happens when individuals have the total loss of "human rights", whether in the submission of adults, children or teenagers to forced labor to pay debts assumed by themselves or the family, or by financial necessity for subsistence. In this context, we can include activities to support agriculture, mining, industries in general, and sexual exploitation of minors or women, where there is induction to crime, involvement with drugs and propensity to death, requiring the intervention of the police, the Justice and the State for correction (Strelhow, 2014);

m) Prejudice and exclusion: of race; skin color; social class; physical or intellectual disability, etc. We can include homophobia in this context; femicide; and sexual abuse or submission of women, children or adolescents, by improper use of power or crime. This is a case of extreme violence to the like, where there is total subtraction of constitutional rights $\left(\mathrm{CF} / 88^{3}\right.$, Art. 243) and human Rights (Universal Declaration

\footnotetext{
${ }^{3}$ CONSTITUTION OF THE FEDERATIVE REPUBLIC OF BRAZIL OF 1988, Article no 243; Available at: <http://www.planalto.gov.br/ccivil_03/constituicao/>.
} 
of human ${ }^{4}$ rights - Dudh, 2009), constituting in Criminal penalty, according to the Brazilian Penal code (Strelhow, 2014);

n) Bullying: It is the excesses committed by employers through physical and psychological aggressions such as persecution, exclusion, exposure and disrespect. Slavery was abolished many years ago; however, one can whip an individual with overwork, by pure "pleasure" in humiliating an individual to the others. The "debauchery and humiliation" before the team can lead the individual to pain, anguish, and depression, which result in revolt, madness or death. Globalization, technology and automation have brought the huge competivity that, in turn, generates the need for substantial increase in productivity to meet the goals and achieve the best results, which triggers the tensions and collections that generate the Stress to occupational diseases (Bruginski, 2013).

\subsection{Consequences of Stress}

Most of the diseases caused by stress have already been cited in the previous subtitle, but we can add the stress-generated syndromes, which are difficult to control, which are in a research situation. We can relate as main consequences:

1) Burnout ${ }^{5}$ syndrome: Psychic disorder of depressive character, preceded by intense physical and mental exhaustion. It is defined as a negative reaction associated with chronic occupational stress, which occurs in three dimensions: 1st) Emotional exhaustion, characterized by a feeling of lack of energy and exhaustion, with feelings of hopelessness, sadness, irritability until Weakness, headache, nausea, musculoskeletal disorders and sleep; 2) depersonalization, characterized by attitudes of distancing, lack of interest and alienation in relation to social and work groups; and 3) decrease of personal accomplishment in the work that causes low productivity, making the individual unhappy and dissatisfied with his/her professional life. It is very common among professionals working on oil rigs due to excessive confinement; Peculiarities of the work; exposure to eminent risks; too much heat or cold; lack of illumination; Etc. It is also known as "occupational exhaustion syndrome" (Dias, 2016);

2) The stress of care: This is another occupational stress that does not abandon nursing professionals. Some researchers say that this stress is directly linked to the day life but it is stimulated by important factors such as exposure to pathological agents; Fatigue with the time zone "versus" the biological spindle; Workload accumulation; The constant relationship with the cycle "life and Death", which generate physical and mental health problems; Living with human suffering; The need for a huge productive performance; The adequacy to the hospital dialectical life, which directly influences the personal life of these people; The prevailing contradiction and conflict

\footnotetext{
${ }^{4}$ Universal Declaration of Human Rights of 2009, established by the United Nations General Assembly (UN), updated in 2018; Available at: 〈https://nacoesunidas.org/wp-content/uploads/2018/10/DUDH.pdf〉.

${ }_{5}$ Burnout, of English vocabulary, means "to burn to the end", which defines what happens to patients with this syndrome.
} 
over harmony and consensus; The constant conflict between change and stability; excessive emotional burden; and daily coping with stressful events. This case is more evident among the nursing of public health organizations (Fernandes \& Medeiros \& Ribeiro, 2008);

3) Neuropsychiatric diseases: persecution mania; phobias; anxiety; depression; insomnia; psychosis; and others needing treatment and psychiatric follow-up (Cataldi, 2015);

4) Pathologies due to low immunity: There is a wide variety of viruses, bacteria and fungi to which, normally, the organism of the non-stressed individual has conditions to offer resistance, but the stressed can no longer resist and comes to succumb to the disease (Cataldi, 2015);

5) Consequent pathologies: gastric problems; increased epithelial allergies; hypertension; bronchial asthma; cardiopathies; stroke cerebral and cardiac ischemia; Nephrological diseases; Cardiac arrhythmia; Respiratory insufficiency; Circulatory and etc. (Cataldi, 2015);

6) Social problems: Consequent changes in family relationships, with friends, with coworkers, and in social groups in general. In this context, we can find the individual in isolation (absenteeism) or very altered in presenteeism (where he seeks to attack others to make himself present) and may generate feelings of vengeance that can lead to the practice of an offence (Cataldi, 2015).

\subsection{Solutions and Treatment}

The author Álvaro Tamayo (2001), based on results obtained in research from the most diverse groups of workers, states that individuals who exercise a moderate physical activity associated with axial movements have good physical conditioning and therefore, are much less vulnerable to occupational stress. Thus, it was verified that the activity and physical conditioning should be implemented as a priority in the prevention, treatment and combating of physiological, psychological and social stress. It was observed that physical activity has more impact on the fight against stress in adult individuals aged between 25 and 46 years, where the motivational tendencies of people were observed, expressing what they want for themselves and for society (Crews and Landers As cited in Tamayo, 2001, p. 132).

Thus, the applicable solution will depend on the level of stress of each individual, whether there is pathology to be treated and the origin of the stressful factors that must be extinct. If an organization does not express the willingness to change attitude due to the welfare of its intellectual heritage, the immediate decision is to treat the individual and convince him to change work. Preponderating is only possible through an emergency situation to avoid disastrous consequences, provided that a specialist makes a prior clinical diagnosis. Therefore, we need to consider as axiological priorities the activity and physical conditioning of workers in the fight against Labor stress, which also extends to employers as a key factor of success and maintenance of business (Tamayo, 2001). 
It is essential that actions be implemented that enable the Association of work with human rights as a factor of improvement in totalitarian organizations, as these, according to Meneghetti (2018): "[...] they aim to "per se" The systematic extermination of people [...] ". Meneghetti spent the last ten years doing readings, studies, researches and analyses of these organizations to understand their general context, because they emerge and how they operate in the "modus operandi", besides deepening in their foundations. In the aforementioned investigation, totalitarian organizations are compared to Nazi extermination groups, regime institutions and Soviet police, compared to the atrocities suffered by the Jews (Meneghetti, 2018).

On the other hand, we know that the right to work is inserted into universal human rights, before which the human being is seen as a disconnection of reality, free and equal to other beings on the planet, where labor relations must be exchanges naturally established, without the image of individuals regulated by contracts. However, through the socioeconomic issues of today, human rights are nothing but "dust that serves to support the lens of the real vision of Things" (Meneghetti, 2018, p. 1372).

We cannot generalize business because there are large companies such as ROCHE, for example, who have already been using the strategy of deploying a gym within its industrial complex since 2011, so that employees have physical activity as part of Functions, because by preventing and controlling stress they can increase production and value their human resources. In this case, work and human rights live harmoniously for the good of all: economics, social, collaborators and others (source: authors).

\section{Method}

This study is a descriptive research, by the function of writing the characteristics of a group or population.

The descriptive research for Gil (1999), aims to study the characteristics of a group of individuals, and thus the attitudes, beliefs and opinions of these can be addressed. Also agreeing with Gil (1999), Triviños (1987) stresses that the descriptive study aims to "accurately describe the facts and phenomena of a given reality". Vergara (2013) points out that descriptive research has the function of exposing some characteristics of a determined group or some phenomenon.

At the same time the descriptive study was conducted a bibliographic research and used the Bibliometric analysis technique, which according to Souza \& Ribeiro (2013) is a technique that is based on quantifying and analyzing the material produced on the subject being Studied. And to seek to supply any deficiency of unique methodologies, Minayo (2008) states that "any social research that intends a deeper deepening of reality cannot be restricted to the only quantitative referential".

To begin the study, the search for articles published in the last 10 years, from 2008 to 2019, on the topic occupational stress and the databases chosen for the reliability and public recognition were the Scientific Electronic Library Online (SciELO) in Brazil and the Scientific Periodicals Electronic Library (SPELL). 


\section{1) Macrothink}

International Journal of Human Resource Studies

ISSN 2162-3058

2019, Vol. 9, No. 4

To perform the search of the articles, we used the technique of searches using the keywords: occupational stress, stressors in the workplace, organizational violence.

When searching using the criterion of the keywords, 145 articles were found in the Scielo and 22 articles in the Spell, and no article was found that contained the keywords stressors in the workplace and organizational violence. All the articles found were by the keyword occupational stress.

With the Bibliometric analysis technique, it was possible to identify which areas were most researched on stress, what types of research and which groups are most researched and from data collection, a data quantification was performed.

\section{Analysis and Results}

This stage will be presented the results obtained in the research based on the searches performed on the platforms scientific Electronic Library Online (SciELO) of Brazil and the scientific Periodicals Electronic Library (SPELL).

To present the analysis of the data obtained in this study, the following data collection is presented in the format of tables, graphs with the appropriate percentages and explanatory texts on each category analysed.

In the development of this article, based only on 167 articles analysed with the theme stress and with reference in the keywords used, we obtained the following results:

We found that it is used more frequently, in terms of characterization of the research, according to table and graph 1 below, the quantitative approach is the most used and represents $61 \%$ (102 articles), followed by bibliographic review surveys with 21\% (35 and the quantitative approach totalizing 16\% (26 articles). We verified that the quali/quanti approach proved to be less usual with $2 \%$ (4 articles).

Table 1. Most Commonly Used Search Types

\begin{tabular}{l|r|r|r|r}
\hline KEY WORD & Quant & Qual & Bib. Rev. & Qual X Quant \\
\hline OCCUPATIONAL STRESS & 102 & 26 & 35 & 4 \\
\hline ORGANIZATIONAL VIOLENCE & 0 & 0 & 0 & 0 \\
\hline STRESSORS IN THE WORKPLACE & 0 & 0 & 0 & 0 \\
\hline
\end{tabular}

Source: Search Data (2019) 


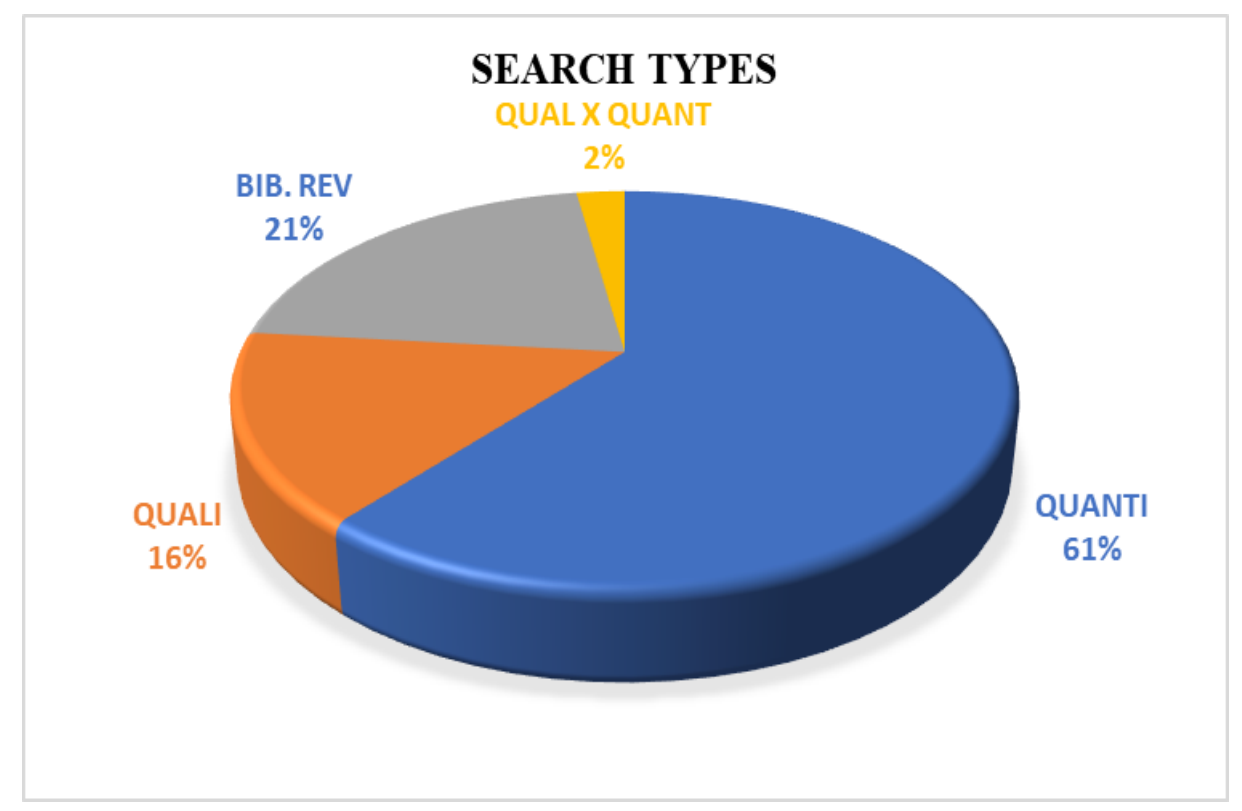

Figure 1. Most Used Search Types

Source: Search Data 2019.

As for the sectors that most were found studies on stress, according to table 2 and Graph 2 show, the public represents $44 \%$ ( 74 articles), while in the private $19 \%$ (32 articles). Other sectors had a high percentage of $37 \%$ (61 articles), but as the percentage of bibliographic review surveys is high, it also does not identify the sector, because it is based only on the review. Some articles analysed had researches in both public and private environments, such as hospitals and banks.

Table 2. Sector with More Research on Stress

\begin{tabular}{l|r|r|r|r}
\hline KEY WORD & SCIELO/SPELL & Public & Private & \multicolumn{2}{|c}{ Other } \\
\hline OCCUPATIONAL STRESS & 167 & 74 & 32 & 61 \\
\hline ORGANIZATIONAL VIOLENCE & 0 & 0 & 0 & 0 \\
\hline STRESSORS IN THE WORKPLACE & 0 & 0 & 0 & 0 \\
\hline
\end{tabular}

Source: Search Data 2019. 


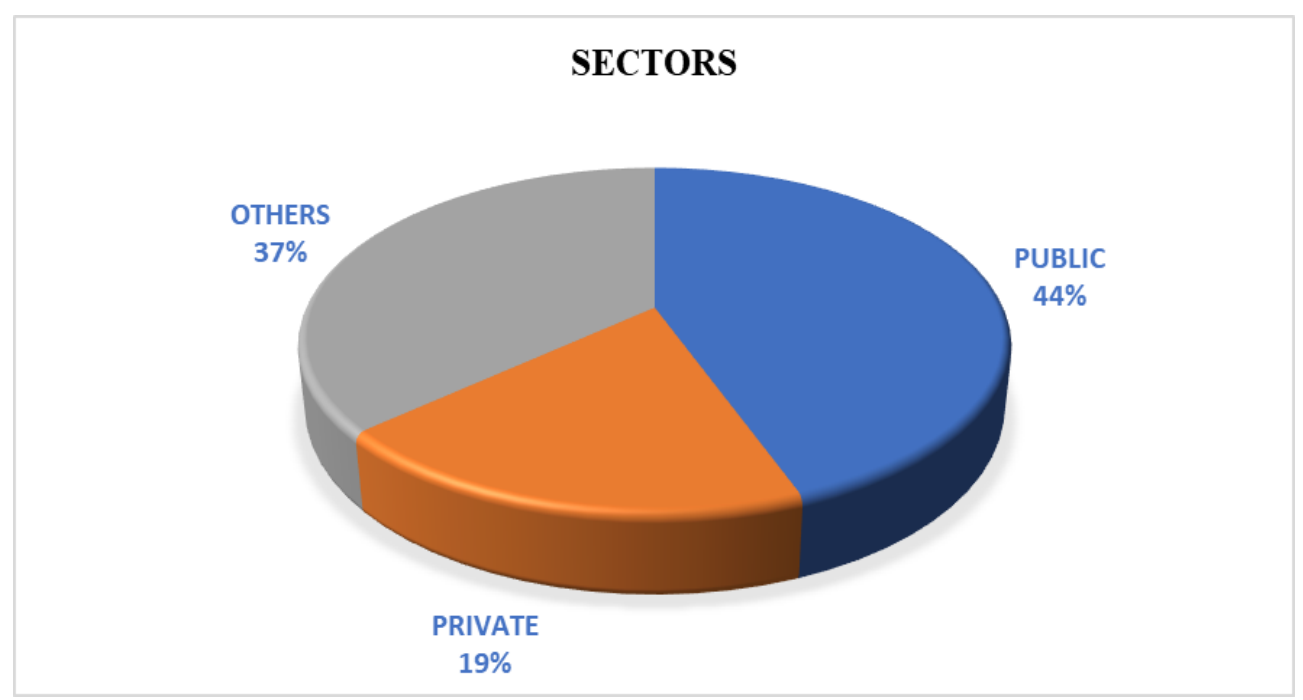

Figure 2. Sector With More Research On Stress (\%)

Source: Search Data 2019.

When analyzing which groups are researched, some articles are very punctual and make clear the work area. Some groups are well diversified and would not have so much presence if they were quantified and entered the framework "others (general services, construction, children, telemarketing, financial, administrative and bibliographical revisions that do not define the group analysed) ". In the health area, which has a greater number of related articles, it represents $47 \%$ (78 articles), followed by education with 14\% (23) and military with 10\% (17), which include firefighters, police and others of public safety. In the other group, because it is so diverse, it has a high percentage of $29 \%$ with 49 associated articles.

Table 3. Working Groups

\begin{tabular}{l|r|r|r|r|r}
\hline KEY WORD & SCIELO/SPELL & Health & Military & Education & Other \\
\hline $\begin{array}{l}\text { OCCUPATIONAL } \\
\text { STRESS }\end{array}$ & 167 & 78 & 17 & 23 & 49 \\
\hline $\begin{array}{l}\text { ORGANIZATIONAL } \\
\text { VIOLENCE }\end{array}$ & 0 & 0 & 0 & 0 & 0 \\
\hline $\begin{array}{l}\text { STRESSORS IN } \\
\text { THE WORKPLACE }\end{array}$ & 0 & 0 & 0 & 0 & 0 \\
\hline
\end{tabular}

Source: Search Data 2019. 


\section{WORKING GROUPS}

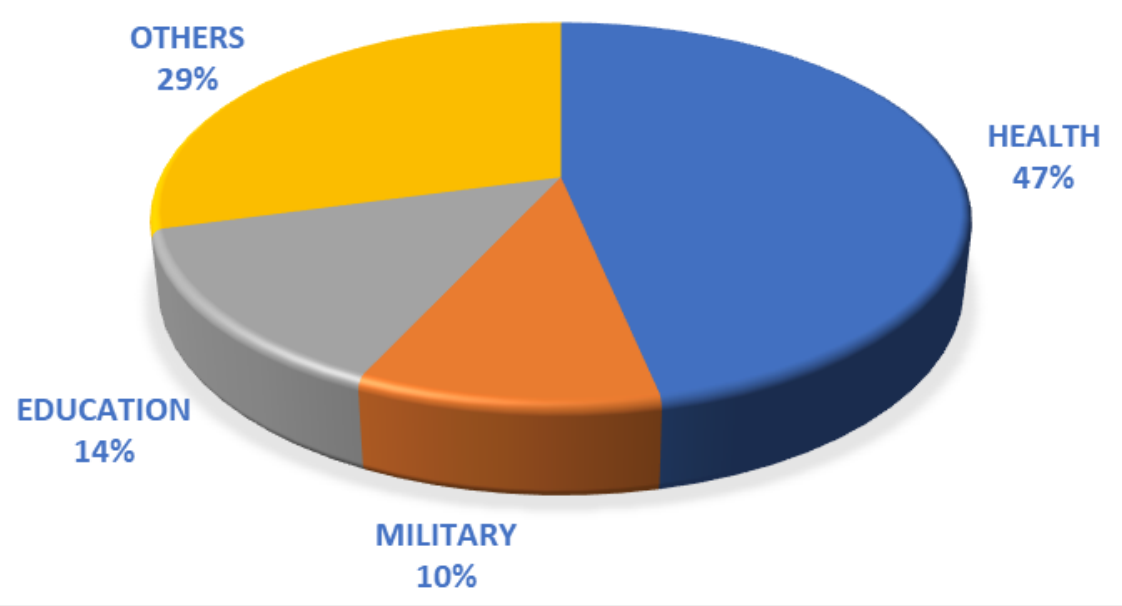

Figure 3. Working Groups (\%)

Source: Search Data 2019.

Publications between 2008 and 2013 were well approximated with percentages between 5 and 7\%, with the exception of 2010 that reached $8 \%$ (13 articles) of the articles analysed, as shown in table 4 and Chart 4. From 2014 onwards they increased almost double, reaching $12 \%$ (20 articles) this year and 15\% (25 articles) the following year. Slight decrease in the two consecutive years, with percentages of 11\% (18 articles) and 9\% (16 articles), arriving in the last year to sustain 15\%, reaching the same peak of 2014.

Table 4. Year of Publication

\begin{tabular}{l|r|r|r|r|r|r|r|r|r|r|r}
\hline KEY WORD & 2008 & 2009 & 2010 & 2011 & 2012 & 2013 & 2014 & 2015 & 2016 & 2017 & 2018 \\
\hline OCCUPATIONAL STRESS & 9 & 10 & 13 & 11 & 10 & 10 & 20 & 25 & 18 & 16 & 25 \\
\hline $\begin{array}{l}\text { ORGANIZATIONAL } \\
\text { VIOLENCE }\end{array}$ & 0 & 0 & 0 & 0 & 0 & 0 & 0 & 0 & 0 & 0 & 0 \\
\hline $\begin{array}{l}\text { STRESSORS IN THE } \\
\text { WORKPLACE }\end{array}$ & 0 & 0 & 0 & 0 & 0 & 0 & 0 & 0 & 0 & 0 & 0 \\
\hline
\end{tabular}

Source: Search Data 2019. 


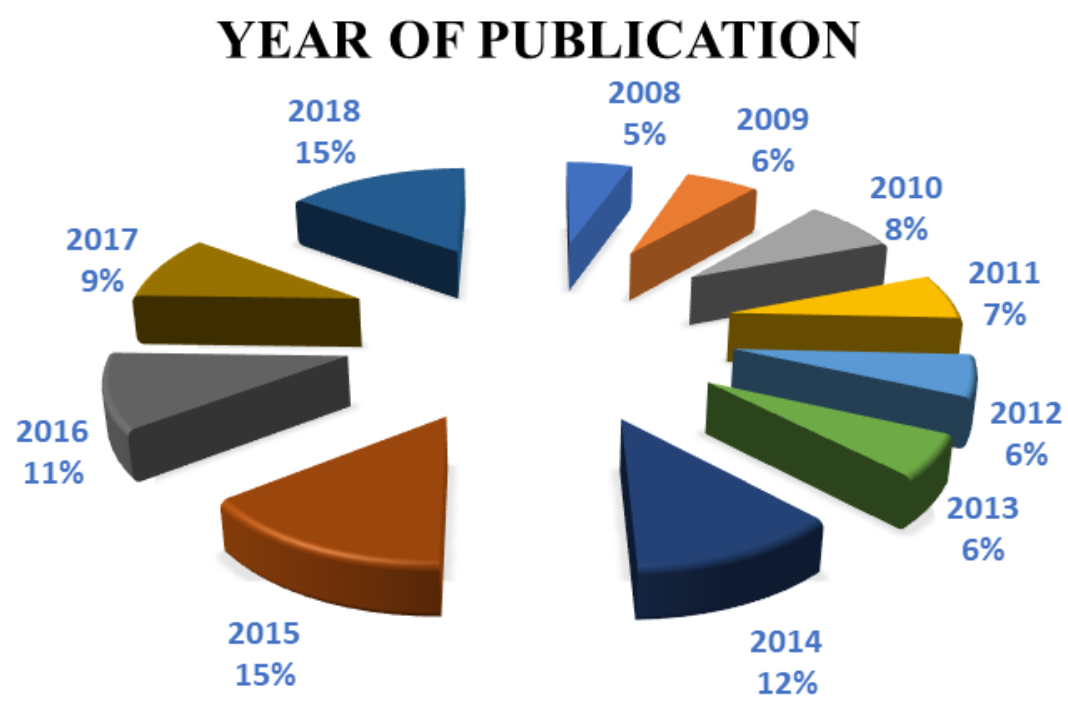

Figure 4. Year of Publication (\%)

Source: Search Data 2019.

Graph 5 shows how the publications evolved during the 10-year period surveyed, from 2008 to 2018. From 2014 onwards there is a very significant growth in relation to previous years, which remained almost stable from 2008 to 2013, with minimum increase in 2010. In the year 2015 the publications on occupational stress were their totality, decaying in the following two years and returning to the same index in 2018.

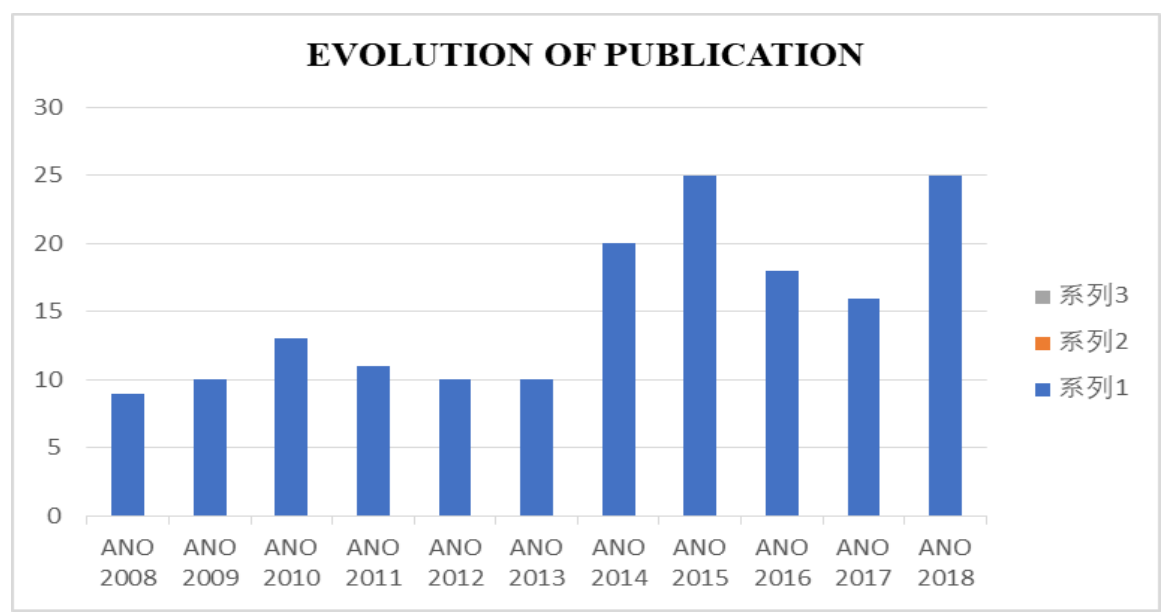

Figure 5. Evolution of Publication

Source: Search Data 2019.

\section{Conclusion and Recommendations}

This article is based on a bibliographic reference for the importance of occupational stress nowadays, whether to combat totalitarianism, intransigence, abuse, disrespect or impartiality in organizations. The actions of prevention, control and treatment of occupational stress 
should be effective tools for improvement, increasing the productivity of companies and providing the creation of "value" for both organizations and workers.

Employers need to change the look on the worker and have the vision of "internal customer" and that to produce needs to be motivated and, consequently, can act in synergy, with each other, in the search for the objectives of the company, restricting itself to the mission, Vision, goals and values. One of the most important strategies to be implemented in a company is internal marketing, which is geared specifically to internal customers because it provides the creation and review of goals, objectives and values of the business, in addition to enabling Implementation of improvements in organizational culture and ambience.

The changes should start at the higher level, radiating to the others, so that the internal target is known and satisfied, from the search for its sustainability, productivity and satisfaction of the needs and desires of all: Company, employees and general population.

We believe that the objectives presented here were satisfactorily achieved, but we hope that, through this study we can answer the question here guided. That in the next ten years of this century, it is possible to find investigations with different realities, with incentives for improvements that provide the increment of innovative actions and methods in the organizational environment due to the welfare of Employers and collaborators.

In the data analysis indicates that they still need researches focused on occupational stress, although it has been performed on the basis of only two of the study platforms, there is still room for further discussion and post-intervention research for terms Knowledge if the strategies used bring positive feedback. Mainly in the health area, which works in environments conducive to illness, it is to be worked and mainly with qualitative research, because the observation can seek information that numerical data cannot, such as pain, pleasure and that cannot be measured with questionnaires and quantitative.

\section{References}

Amaral, M. A. (2013). Occupational Stress: A study of the work relations of the Municipal Health Center of Iúna/Es. X Symposium of Excellence in Management and technology. Resende, RJ: P. 1-15.

Bruginski, M. K. (2013). Bullying at work-concept, species and requirements characterizers. Electronic magazine. Rio de Janeiro.

Cataldi, M. J. G. (2015). Stress in the workplace environment. São Paulo: LTR, ed. 3rd, Oct.

Costa, M., Junior, H. A., Oliveira, J., \& Maia, E. (2007). Stress: diagnosis of military police personnel in a Brazilian city. Revista panamericana de salud publica= Pan American journal of public health, 21(4), 217-222.

Dias, F. M., Santos, J. F. D. C., Abelha, L., \& Lovisi, G. M. (2016). Occupational stress and professional exhaustion syndrome (burnout) in workers from the petroleum industry: a systematic review. Revista Brasileira de Saúde Ocupacional, 41. 


\section{Macrothink}

International Journal of Human Resource Studies

ISSN 2162-3058

2019, Vol. 9, No. 4

Fernandes, S. M. B. de A., Medeiros, M., \& Ribeiro, L. M. (2008). Occupational Stress and the current world of work: repercussions in the daily life of nurses. Electronic Journal of Nursing, $10(2), 414-427$.

Gil, A. C. (1999). Social Research methods and techniques. 5. ed. São Paulo: Atlas, 1999.206p.

Herkenhoff, F. (2007). Occupational Stress and systemic arterial hypertension. Brazilian Journal of Hypertension, 4(2), 112-115.

Minayo, M. C. S. (2008). The challenge of knowledge. 11 ed. São Paulo: Hucitec.

Meneghetti, Francis Kanashiro (2018). Totalitarian organizations: Modus Operandi and Fundamentals. Journal of Administration and Communication. Rio de Janeiro: v. 22, N. 6, p. 841-858, Nov/Dec.

Paschoal, T., \& Tamayo, A. (2005). Impact of labor values and family interference occupational stress work. Psychology magazine: Theory and research, 21(2), 173-180,

Pereira, J. G., \& Mello, F. (2016). Causes and effects of stress at work. UNIS University. UNIS Magazine. Minas Gerais: P. 146-164, May.

Prado, C. E. P. (2016). Occupational Stress: Causes and consequences. Brazilian Journal of Occupational Medicine, 14(3), 285-289.

Silva, V. E. D. (2010). The totalitarianism in Hannah Arendt. University of Porto. Thesis (master's in philosophy - ethics and political philosophy).

Silva, Leandra. C., \& Salles, T. L. de A. (2016). Occupational stress and alternative forms of treatment. Careers and People magazine, 6(2), 234-247.

Sousa, M. C. (2017). Occupational Stress: Main Concepts According to psychiatry. HSO-PMC Magazine. Rio de Janeiro.

Souza, J., \& Ribeiro, I. (2013). People Management Policies in a nonprofit organization in the state of Paraná - Brazil. Electronic continent magazine of administration and tourism, $1(1), 29-37$.

Strelhow, T. M. P. B. (2014). Work relations and human rights: A possible association? II International Congress of the Faculty of the Espirito Santo, 2, 1371-1382.

Tamayo, A. (2001). Axiological Priorities, Physical activity and occupational stress. Journal of Administration and Communication, 5(3), 127-147.

Triviños, A. N. S. (1987) Introduction to research in social sciences: Qualitative research in education. São Paulo: Atlas, 175p.

Vergara, Sylvia Constant (2013). Research projects and reports in administration. 14. ed. São Paulo: Atlas. 


\section{Copyright Disclaimer}

Copyright for this article is retained by the author(s), with first publication rights granted to the journal.

This is an open-access article distributed under the terms and conditions of the Creative Commons Attribution license (http://creativecommons.org/licenses/by/4.0/). 